\title{
Accreditation in hospitals: Should we implement the same standards in different types of hospitals? The case of a mental health hospital
}

\author{
Isaak $\mathrm{V}^{1 *}$ and Steiner- Lavi $\mathrm{O}^{2}$ \\ ${ }^{1}$ Management Faculty, MLA The College for Academic Studies, Israel. \\ ${ }^{2}$ Management Faculty, MLA The College for Academic Studies, Israel. \\ ${ }^{\star}$ Correspondence to: Valerie Isaak, Management Faculty, MLA College for Academic Studies, Israel; Tel: +972 526095117; Fax +972 (3) 7354445; \\ Email: valerie.isaak@gmail.com
}

Received: June 23, 2018; Accepted: July 02, 2018; Published: July 08, 2018;

\begin{abstract}
In the era of implementing quality standards as a mandatory process toward licensing, we raise the issue of implementing a generic standards for hospitals, or organizations, in general. Should we set different standards for different types of hospitals that implement to standards? This case study explores the specific issues that raise the dilemma. Regarding the fact that this hospital is the first mental health hospital in Israel to adopt the quality standards, it is crucial to understand the issue of adjusting the solutions for quality care.
\end{abstract}

Keywords: Accreditation, Quality service, Hospital types

\section{Introduction}

In the current era of globalization and the rapid changes that come with it, most governments are trying to improve management efficiency processes and performance [1,2]. Since the 1980s, public reform has expanded around the world, in particular as a result of public pressure to improve services in exchange for the tax burden imposed on citizens $[2,3]$.

As we know, over the past several decades, Israel's governments have adopted various reforms; the main one being privatized [4], which has led to competition in all areas of life, including healthcare services [5]. Healthcare organizations in Israel now face challenges such as reducing resources, narrowing the budget share, balancing the load in hospitals and improving quality of service. In light of this, the question of "how to provide quality care?" has been raised. In the next section, we will present the latest healthcare system reform in general and specifically in hospitals, in particular to Accreditation standards and the benefit to quality services [6].

Accreditation is a structured process of recognizing and promoting performance and adherence to standards either received from an authorized body or those that are newly developed, including updated existing standards. It is a system of organizational improvement centered on a certifying agency (or accrediting body) that assesses performance against pre-determined standards $[7,8]$.

Accreditation services in hospitals began around 1910 in the USA. The Association of American Surgeons has been promoting quality standards to increase safety and safety awareness in more than 16,000 healthcare facilities in the USA. The organization has an international arm known as "Joint Commission International" (JCI), which currently operates in countries around the world and throughout Europe, South Africa, the Far East and Middle East [9].

Research shows that healthcare organizations benefit from increased quality service through the implementation of accreditation standards. The benefit of accreditation includes: patient safety and reduced clinical risk and others [10,11], promotion of quality improvement activities, Implementation of processes that promote improvement, effective management [12], increased organizational learning $[13,14]$, improved organizational reputation $[8,15]$, improve organizational communication and cooperation between the staff and the community $[10,12,13]$, and reduction in the cost of claims [16]. Studies shows that there is a correlation between clinical performances, safety and patient outcomes, and the implementation of accreditation [17].

At the national level, the agency responsible for carrying out quality improvement is the Ministry of Health's Quality Assurance Department. They are tasked with overseeing quality assurance standards that meet national and accreditation-like system operations [6]. Due to the advantages of working in accordance with international standards for improving the quality and safety of care, the Health Ministry Director General decided at 2012 that hospital accreditation is a prerequisite for a licensing of all the general hospitals in Israel. For other hospitals (such as mental health hospitals) it is not mandatory. The JCI organization and their standards were selected by Israel's Ministry of Health to be the competent authority for accreditation. 


\section{Case study}

Accreditation standards exist for different types of health organizations such as hospitals, medical laboratories, home health care, nursing services, ambulatory services, medical transportation, etc. [18]. At the same time, we are not aware of specific standards for psychiatric hospitals. The Sha'ar Menashe Mental Health Center is the first psychiatric hospital in the world, to the best of our knowledge, to adopt the accreditation standard for all its departments.

The purpose of this article is to examine the decision of Shaar Menashe Hospital to fully implement the accreditation standard. It should be noted that the standard is adapted to general hospitals on the basis of their characteristics, which differ significantly from psychiatric hospitals. For example, in a general hospital, a patient is usually in need of treatment for a short period of time, several days to weeks. On the other hand, in a psychiatric hospital, a patient can stay in for treatment for a long period of time, which could last for months or even years. Treatment characteristics and the nature of patients are different and there is a long-standing acquaintance with patients in psychiatric hospitals [19].

The different characteristics of the types of organizations in addition to long-term acquaintance with the patient necessitate a different managerial approach [19]. In light of the above, we would like to examine whether the decision to adopt a standard intended for general hospitals in psychiatric hospitals is a correct decision and was it necessary to make adjustments before implementing the standard?

Regarding the attempt to implement the necessary standards of the JCI, Shaar Menashe mental health hospital's managers have built a framework of standardization. The hospital had good work processes till that time, but the willing to adopt the new standards led to build the processes in the proper time constraints of the JCI. Most of the issues focused on schedule, oriented to the patient secure, such as: 5 day program for new patient, patient' identification, mammography, patients' discharge, summery of detailed disease within two weeks of discharge, ensuring continuity of treatment after release in the community for further treatment in the community.

After a process of more than a year in an attempt to meet the requirements of the accreditation standard at the Shaar Menashe Hospital and following the learning process, we have decided to present in this article as a case study the case of securing the patient through proper identification. In light of the general hospitals, clinical risks such as misidentification of patients that led to the wrong treatment, one of the major JCI standards is the proper patient identification clinical risk events. In order to reach the standard of this issue, the general hospital's quality assurance solve the identification problem by adopting the process of attaching an identification handcuff on the patient's hand. In an era in which we are required to use a variety of means to identify citizens (such as identification by means of a biometric ID), it is logical that this requirement will be a core requirement of an organization such as a hospital relative to its patients. It is known that in general hospitals, where there is a very high turnover rate of patients and attendants, and in order to prevent mistakes and unusual events (such as incorrect treatment of the patient), it is very important to attach an identification handcuff to the patient. On the other hand, in psychiatric hospitals where there are patients who stay for a long period of time and with minimum attendant's turnover, the question arises whether there is a need to attach a handcuff or is there an alternative solution that can be used. It is important to note that examination of this requirement of the standard is not arbitrary. In fact, from the moment the decision was made at the Shaar Menashe Hospital, the therapists were forced to deal daily with patients who teared the handcuffs from their hands, wasting time on attaching a new handcuff to the patient's hand and the economic costs incurred by the hospital in light of the widespread phenomenon. Every day, therapists face the challenge of spending precious time in preparing a patient plan, departmental activities for the patient, and more. Nevertheless, this financial expenditure to the hospital was available and it was possible to invest these resources, in infrastructure or in any means to improve the conditions of hospitalization and the level of treatment that patients receive. It seems that the same demands for organizations with different characteristics, even though they are in the same field, are an issue that needs to be considered. In other words, it is necessary to examine whether it was correct to create adjustments based on the characteristics of the organization.

\section{Conclusions and Recommendations}

A mental health hospital has to deal with unique issues which differ from the general hospital ones. For instance, one of the major issues of patients' safety is seaside prevent. Yet, the need to meet the JCI standards under the health ministry regulations brought the quality assurance managers in the hospital to focus on those of the general hospital ones.

After examining this case and presenting the dilemma that arises from the requirement of the standard for attaching the patient's handcuff identification, we bring the constant dilemma that arises when implementing generic standards - should the same standard be implemented in organizations with different characteristics? Organizational management standards are required for efficiency and organizational effectiveness, and mainly for managerial control. However, this issue should be examined in terms of organizational characteristics. In the present case, it could be more efficient, in our opinion, to examine the significance of the decision in light of the characteristics of the psychiatric hospital and to make adjustments. For example, we would recommend that the hospital, in the era of information technology, makes use of the digital medical record that each patient has and add the patient's digital (or biometric) picture. Thus, at any time, the staff will be able to check the correlation between the patient in care and his record to which a picture was added. Even if we would assume that in most cases the staff is well acquainted with the patient, this implement provides a solution to situations in which there is no prior acquaintance. We can see that in many areas of our lives, we are required to meet the means of identification and today there are many technological means such as the biometric identification that could be adopted for this case. We must strive to introduce accreditation in managerial control, while adapting to the characteristics of unique organizations.

The health ministry encourages the hospitals to get the JCI accreditation (while in the general hospitals it is mandatory). Thus, it 
would be a benefit if the health ministry will present unique solutions for the mental health hospitals in a way that will help them to meet the JCI standards with solutions that meet their needs, while managing the resource utilization wisely, especially toward implementing the JCI standards in.

A quality care for the patients demands not only reaching the goal standards, but getting innovative solutions as well.

\section{References}

1. Kettl DF (2005) The global public management revolution. $2^{\text {nd }}$ (edn). Washington DC: The Brookings Institution, USA.

2. Pollitt C, Bouckaert G (2004) Public management reform: a comparative analysis. Oxford: Oxford Press University, United Kingdom.

3. Osborne D, Gaebler T (1992) Reinventing government. New York: Plume, USA.

4. Galnoor I, Rosenbloom DH, Yaroni A (1998) Creating new public management reforms: lessons from Israel. Adm Soc 30: 393-420.

5. Cohen N (2013) The self-provision of public healthcare services: a threat of democracy. J Politics Law 6: 128-133.

6. Amit N, Livny N, Lev B (2006) The role of the ministry of health in quality promotion. In: Porat A, Rozen B (eds). Quality forum-quality promoting strategy. Jerusalem Smokler Center.

7. Braithwaite J, Westbrook J, Johnston B, Clark S, Brandon M, et al. (2011) Strengthening organizational performance through accreditation research-a framework for twelve interrelated studies: the accredit project study protocol. BMC Res Notes 4: 390-398. [crossref]

8. El-Jardali F, Jamal D, Dimassi H, Ammar W, Tchaghchaghian V (2008) The impact of hospital accreditation on quality of care: perception of Lebanese nurses. Int $J$ Qual Health Care 20: 363-371. [crossref]

9. Mahmoud-Salim F, Rahman MH (2017) The impact of joint commission international healthcare accreditation on infection control performance: a study in Dubai Hospital. Global Journal of Business \& Social Review 5: 37-45.

10. Simons R, Kasic S, Kirkpatric A, Vertesi L, Phang T, et al. (2002) Relative importance of designation and accreditation of trauma center during evolution of a regional trauma system. J Trauma 52: 827-834. [crossref]

11. Griffith JR, Knutzen SR, Alexander JA (2002) Structural versus outcomes measures in hospitals: a comparison of Joint Commission and Medicare outcomes scores in hospitals. Qual Manag Health Care 10: 29-38. [crossref]

12. Sutherland K, Leatherman,S (2006) Regulation and quality improvement: a review of the evidence. London: The Health Foundation, United Kingdom.

13. Pomey MP, François P, Contandriopoulos AP, Tosh A, Bertrand D (2005) Paradoxes of French accreditation. Qual Saf Health Care 14: 51-55. [crossref]

14. Touati N, Pomey MP (2009) Accreditation at a crossroads: are we on the right track? Health Policy 90: 156-165. [crossref]

15. Bird SM, Cox D, Farewell VT, Goldstein H, Holt T, Smith P (2005) Performance indicators: good, bad and ugly. J R Stat Soc Ser A Stat Soc 168: 1-27.

16. Lewis $S$ (2009) Accreditation in health care and education: The promise, the performance, and lessons learned. Dubai: Access Consulting Ltd, UAE.

17. Thornlow DK, Merwin E (2009) Managing to improve quality: The relationship between accreditation standards, safety practices, and patient outcomes. Health Care Manage Rev 34: 262-272. [crossref]

18. Jovanovic B (2005) Hospital accreditation as method for assessing quality in healthcare. Arch Oncol 13: 156-157.

19. Jones K, Sidebotham R (2013) Mental hospital at work. London: Routledge, United Kingdom.

\section{Citation:}

Isaak V, Steiner- Lavi O (2018) Accreditation in hospitals: Should we implement the same standards in different types of hospitals? The case of a mental health hospital. Ageing Sci Ment Health Stud Volume 2(3): 1-3 